Article

\title{
Experimental Study of a New Strengthening Technique of RC Beams Using Prestressed NSM CFRP Bars
}

\author{
Vicente Alcaraz Carrillo de Albornoz ${ }^{1, *(\mathbb{D}, \text { Eva M. García del Toro }}{ }^{2}$, M. Isabel Más-López ${ }^{2}$ and \\ Alfredo Luizaga Patiño ${ }^{2}$ \\ 1 ETSICCP, Universidad Politécnica de Madrid, 28040 Madrid, Spain \\ 2 ETSIC, Universidad Politécnica de Madrid, 28040 Madrid, Spain; evamaria.garcia@upm.es (E.M.G.d.T.); \\ mariaisabel.mas@upm.es (M.I.M-L.); martin.luizaga@upm.es (A.L.P.) \\ * Correspondence: vicente.alcarazc@upm.es
}

Received: 31 January 2019; Accepted: 27 February 2019; Published: 5 March 2019

check for updates

\begin{abstract}
The reinforcement of structural elements subjected to bending with carbon fiber reinforced polymers (CFRP) located on the underside of the element to be reinforced (known as near surface mounted or NSM) is an effective technique that provides environmentally sustainable solutions in the field of civil engineering. Introducing preloads on the reinforcing elements allows us to maximize the high performance of CFRPs, besides recovering deformations. A new technique to perform the pre-stressing of CFRP bars in NSM configuration is described in this paper. The technique introduces the preload on the rods after they have been placed in the grooves, and with a system that acts and reacts against the beam itself. We also present the results of a testing campaign conducted to determine the effectiveness of said technique. Breakage of the control beams (without reinforcement) was ductile, while breakage of reinforced beams was explosive. Pre-stressing the reinforcing elements allowed us to increase the bearing capacity of the beams $170 \%$ compared to the control beams, also resulting in an increase in the rigidity of the reinforced elements and a decreased cracking of the beam. The results however are only slightly better than those of a conventional CFRP NSM reinforcement, due to the appearance of cavities in the groove where the adhesive didn't manage to penetrate.
\end{abstract}

Keywords: bending reinforcement; pre-stressing; beam; carbon fiber; CFRP; fiber reinforced polymer; NSM; near surface mounted

\section{Introduction}

Reinforced Concrete (RC) is one of the most commonly used materials in the design of structural elements. The life cycle of RC structures depends on several factors, which include natural catastrophes, design errors, defective quality of the materials used, poor execution, modified usage or incorrect maintenance [1].

Despite its wide use, $\mathrm{RC}$ presents a serious drawback: cracking [2]. The solution to this problem is pre-stressed concrete. The pre-stressing is achieved by compressing the concrete, using tensioning steel reinforcements anchored on the concrete itself. Thus, under permanent loads and their use it is possible to avoid tractions [2] and, therefore avoid the appearance of cracks [3].

In the search for sustainability in civil engineering, the trend has been the use of techniques that can restore structural elements that have impaired resistant capacity. The replacement of deteriorated elements of a structure is not always viable, due to high operational, economic and environmental costs [4].

Steel has traditionally been used as a reinforcement material for RC structures. The key disadvantage of this material, when it is not adequately protected, is corrosion [5] that leads to 
an important maintenance cost. As an alternative, there is an active search for other reinforcing materials with the same or better performance in terms of resistance, but without this particular cost downside.

Fiber reinforced polymers (FRP) are emerging as an increasingly popular reinforcement material, manufactured in the form of fabrics, laminates and rods [6]. Of particular interest are carbon fiber reinforced polymers (CFRP), with carbon fibers arranged in one or more directions and agglomerates with a polymer [7]. Besides its resistance to corrosion, CFRP have other advantages, such as: low weight, easy installation, high durability, stress resistance, high deformation capacity, electromagnetic permeability, and availability in different formats [8].

The use of CFRP mainly occurs in two types of configuration: as externally bonded reinforcement (EBR) by placing the reinforcements on the outside of the element to be reinforced, and as a near surface mounted (NSM) reinforcement, by placing the reinforcements inside the element to be reinforced, although very close to its surface. The behavior of RC beams reinforced with NSM CFRP has been extensively studied under both static and fatigue loading [9-11]. The bond mechanism between the reinforcement and the reinforced element has also been researched, analytically and experimentally [12-14]. Other techniques, such as transverse shear reinforcements, have also been studied and documented [15].

Reinforcements in NSM configuration with CFRP rods can significantly increase the load capacity of reinforced concrete beams, especially when the amount of steel in the structural element to be reinforced is relatively low [16]. However, these reinforcements present important disadvantages such as their high price, their low resistance to fire and their fragile behavior, which in combination with RC produce a high performance compound with a low ductile behavior [17]. Also, NSM CFRP as a reinforcement solution is not very efficient, not being capable of significantly modifying the behavior of the reinforced element under service loads [18].

The high tensile strength of CFRP and its relatively low modulus of elasticity mean that the best way to combine it with concrete is through pre-stressing, thus allowing for more efficient reinforcement $[18,19]$. This allows using a greater portion of the CFRP tensile capacity, closes existing cracks and delays the appearance of new ones, and can partially restore deformations of the element to be reinforced.

The pre-stressing of the reinforcement presents however some challenges, due to the fragility of the material and its difficulty to implement both inside and outside the laboratory [12]. In recent years academic literature has been focusing on this subject, investigating both new techniques to pre-stress CFRP NSM reinforcements and the results obtained [18,20-24]. The effects of partial unbounding on prestressed NSM CFRP have also been the object of research [25]. Some research has been carried out as well on prestressed CFRP laminates [26,27].

This study presents a new technique to introduce preloads in reinforcing rods in NSM configuration, which has been patented, and presents the findings of a testing campaign. The proposed method differs from the majority of previous research mainly due to the fact that the CFRP reinforcement is prestressed after it has been mounted on the element to be reinforced, and it jacks and reacts against the concrete beam directly.

\section{Materials and Methods}

\subsection{Materials}

The materials used for the development of the experimental plan were tested and characterized in the Construction Materials laboratory of the Universidad Politécnica de Madrid, ETSIC. 


\subsubsection{Concrete}

The RC beams were fabricated with concrete that is commonly used in construction. The concrete was designed to have a characteristic strength $f_{c k}=20 \mathrm{~N} / \mathrm{mm}^{2}$ and plastic consistency, without the use of additives.

The characteristics of the materials used for the manufacture of concrete were as follows:

- Cement: The cement used to manufacture the concrete was pozzolanic The actual density of the cement was determined by laboratory test [28] and the result obtained was $2.81 \mathrm{~g} / \mathrm{cm}^{3}$.

The mechanical characteristics were also calculated, manufacturing standardized mortar specimens $(40 \times 40 \times 160 \mathrm{~mm})$, by means of kneading and mechanical compaction. The tests yielded a flexural strength of $6.8 \mathrm{~N} / \mathrm{mm}^{2}$ and a compression resistance of $35.9 \mathrm{~N} / \mathrm{mm}^{2}$.

- Aggregates: The sand and coarse aggregates used were crushed siliceous. The maximum size of the aggregates was $12.5 \mathrm{~mm}$. The main characteristics of the sand and gravel that composed the aggregates used were as follows:

Sand: The density of the sand was determined according to the standard [29], obtaining a result of $2.61 \mathrm{~g} / \mathrm{cm}^{3}$. The sand equivalent was calculated according to the standard, obtaining a result of $84 \%$. The granulometric analysis was carried out according to the standard [30]. The results obtained are shown in Table A1 (Appendix A).

G Gravel: The density of the gravel was determined according to the standard [29], with a result of $2.81 \mathrm{~g} / \mathrm{cm}^{3}$. The results of the granulometric analysis are shown in Table A2 (Appendix A).

- Water: The water used in the mixture was drinking water from the public supply network in Madrid.

The concrete dosage was calculated using the Bolomey method. This dosage was used to manufacture all the beams and test specimens used in the tests. Its characteristics are included in Table 1, which provides the quantities that make up a cubic meter of concrete.

Table 1. Dosing of the concrete used in the experimental phase.

\begin{tabular}{cccc}
\hline Material & Density $\left(\mathbf{k g} / \mathbf{m}^{\mathbf{3}}\right)$ & Dosage $\left.\mathbf{( m}^{\mathbf{3}}\right)$ & Dosage $\mathbf{( k g )}$ \\
\hline Concrete & 2810 & 131 & 370 \\
Sand & 2610 & 214 & 560 \\
Gravel & 2810 & 427 & 1200 \\
Water & 1000 & 235 & 235 \\
& Concrete density $=2350 \mathrm{~kg} / \mathrm{m}^{3}$ & \\
& Water / cement ratio $=0.64$ & \\
\hline
\end{tabular}

Once the $f_{c k}=20 \mathrm{~N} / \mathrm{mm}^{2}$ concrete was dosed, measured in a cylindrical specimen of $15 \times 30 \mathrm{~cm}$ at 28 days, the concrete elements to be used in the different tests were fabricated beams of $120 \times 20 \times 10 \mathrm{~cm}$.

It was necessary to make four batches and use cylindrical test pieces of $15 \times 30 \mathrm{~cm}$ from each batch for the Abrams Cone test. The usual process was used as defined by the standards [31,32].

The tests carried out were used to define the mechanical parameters listed in Table 2. 
Table 2. Results of the single compression tests on 4 concrete specimens.

\begin{tabular}{|c|c|c|c|c|}
\hline $\begin{array}{l}\text { Test Specimen } \\
\text { Number }\end{array}$ & Weight (kg) & $\begin{array}{c}\text { Density of } \\
\text { Hardened } \\
\text { Concrete }\left(\mathrm{g} / \mathrm{cm}^{3}\right)\end{array}$ & Maximum Load (T) & $\begin{array}{l}\text { Compression } \\
\text { Resistance } \\
\left(\mathrm{N} / \mathrm{mm}^{2}\right)\end{array}$ \\
\hline 1 & 12.40 & 2.34 & 32.89 & 18.61 \\
\hline 2 & 12.48 & 2.35 & 41.11 & 23.27 \\
\hline 3 & 12.39 & 2.34 & 40.90 & 23.15 \\
\hline 4 & 12.49 & 2.36 & 38.19 & 21.61 \\
\hline
\end{tabular}

The values of the characteristic strength of the concrete were determined based on article 15 of the instruction EHE-08. The characteristic strength of the materials are the quantiles corresponding to a probability of 0.05 . Thus, the characteristic strength of the concrete used was $f_{c k}=18.08 \mathrm{~N} / \mathrm{mm}^{2}$.

The characteristic strength of the concrete to a tensile stress turns out to be, according to the Norm, $f_{c t, m}=2.07 \mathrm{~N} / \mathrm{mm}^{2}$ and $f_{c t k}=2.69 \mathrm{~N} / \mathrm{mm}^{2}$.

The Elastic modulus was $\mathrm{E}=30.001 \mathrm{~N} / \mathrm{mm}^{2}$, and the Poisson's coefficient $\mu=0.111$.

\subsubsection{Steel}

All beams were manufactured using the minimum amount of steel recommended by the EHE. When subjected to a bending test, the exhaustion occurs due to exceeding the elastic limit and the plasticization of the passive reinforcement. Although there is a displacement of the neutral line towards the upper face of the beam that decreases the compression block, eventually this leads to the breakage of the structural part by the plasticization of the compressed head of the concrete. For the assembly, B500S corrugated steel of $6 \mathrm{~mm}$ diameter was used.

A shear reinforcement was also provided in all the beams, to ensure the strength of the beams against this shear effort. The reinforcement was made with 1400 sweet iron of $4 \mathrm{~mm}$ diameter.

The connection of the flexure reinforcement and the stirrups was made with a tie wire.

In the laboratory, tensile tests were carried out on the steel rods, following recognized standards. We used a universal traction equipment of $60 \mathrm{t}$, UIMB-600 of Ibertest. The results of the tests are shown in Table 3.

Table 3. Results of the tests carried out on the steel of the passive reinforcements.

\begin{tabular}{ccc}
\hline Field & Value & Unit \\
\hline Test speed & 0.50 & $\mathrm{kN} / \mathrm{s}$ \\
Section of the test piece & 28.27 & $\mathrm{~mm}$ \\
Maximum applied force & 32.96 & $\mathrm{kN}$ \\
Elastic limit $\left(f_{y}\right)$ & 517.5 & $\mathrm{~N} / \mathrm{mm}^{2}$ \\
Elasticity module $(E)$ & $184,816.7$ & $\mathrm{~N} / \mathrm{mm}^{2}$ \\
Elongation remaining after rupture & 55.55 & $\mathrm{Mm}$ \\
Lower yield limit & 559.6 & $\mathrm{~N} / \mathrm{mm}^{2}$ \\
Upper yield limit & 566.1 & $\mathrm{~N} / \mathrm{mm}^{2}$ \\
\hline
\end{tabular}

\subsubsection{Epoxy Adhesives}

In the present study, two different types of epoxy resins were used: Maxepox CS resin in the shear reinforcement and Maxepox Carbofix resin in the flexural reinforcement.

The maxepox resin CS consists of two components, base resin and normal hardener. An application of a primer on the prepared surface is recommended.

The proportion of the mixture by weight of the base resin and the hardener was 4 to 1 . The final appearance after mixing was intense green. Tests were carried out to verify the mechanical characteristics of the resin and to verify the data provided by the manufacturer. The results obtained were the following: 
- Flexion: 3 prismatic specimens with $4 \times 4 \times 16$ dimensions were tested. An average result of $24 \mathrm{~N} / \mathrm{mm}^{2}$ was obtained.

- Compression: After the flexion test, the test pieces were subjected to a compression test, obtaining an average of $93.22 \mathrm{~N} / \mathrm{mm}^{2}$.

- Adhesion: Two prismatic mortar specimens of $10 \times 10 \mathrm{~cm}$ cross section were used, arranged one after the other longitudinally, and separated by a $20 \mathrm{~mm}$ gap. A longitudinal slit was made on the underside of the specimens, in which a carbon fiber rod $8 \mathrm{~mm}$ in diameter, $20 \mathrm{~cm}$ long, was subsequently housed. The result was not conclusive, although it could be determined that the adhesion is sufficient to guarantee the transfer of loads.

The Maxepox Carbofix resin consists of two components, base resin and normal hardener. In this case, the previous application of a primer on the prepared surface was not necessary. The ratio of the weight mixture of the base resin and the hardener was 2 to 1 . The final appearance after mixing was gray. Tests were carried out to verify the mechanical characteristics of the resin under laboratory conditions and to verify the data provided by the manufacturer. The results obtained were as follows:

- Flexion: 3 prismatic specimens with $4 \times 4 \times 16$ dimensions were tested. An average result of $24 \mathrm{~N} / \mathrm{mm}^{2}$ was obtained.

- Compression: After the bending test, the test pieces were subjected to a compression test, obtaining an average of $93.22 \mathrm{~N} / \mathrm{mm}^{2}$.

- Adherence: Tests similar to those described for the MAXEPOX CS resin were performed, with similar results.

\subsubsection{Carbon Fiber Rods}

The technical characteristics of the material provided by the manufacturer are in Table 4 .

Table 4. Mechanical characteristics of the carbon fiber rods tested.

\begin{tabular}{cccc}
\hline Appearance and color & \multicolumn{3}{c}{ Rod of black color and rough surface } \\
Diametre $(\mathrm{mm})$ & 8 & 10 & 12 \\
Steel equivalent diameter B-500 & 14 & 16 & 20 \\
Cross-sectional area $\left(\mathrm{mm}^{2}\right)$ & 50 & 78 & 110 \\
Guaranteed traction load $(\mathrm{kN})$ & 100 & 156 & 220 \\
Recommended design load $(\mathrm{kN})$ & 70 & 109 & 154 \\
Recommended tensile strength design & & 1400 \\
(MPa) & & 3.00 & \\
Length $(\mathrm{m})$ & 2000 \\
Characteristic tensile strength $(\mathrm{MPa})$ & 150,000 \\
Elasticity module (MPa) & $>1.33$ \\
Deformation in breakage $(\%)$ & &
\end{tabular}

\subsubsection{Fiber Fabric}

The technical characteristics of the material provided by the distributor are attached in Table 5 .

Table 5. Mechanical characteristics of the fiber fabric reinforcement.

\begin{tabular}{cc}
\hline Sheet width $(\mathrm{m})$ & 0.33 \\
Sheet density $\left(\mathrm{g} / \mathrm{mm}^{2}\right)$ & 300 \\
Thickness $(\mathrm{mm})$ & 0.163 \\
Tensile strength $\left(\mathrm{N} / \mathrm{mm}^{2}\right)$ & 2400 \\
Elasticity module $\left(\mathrm{N} / \mathrm{mm}^{2}\right)$ & $4.4 \times 10^{5}$ \\
Break elongation $(\%)$ & 5.5 \\
\hline
\end{tabular}


The reinforcement material is composed of the fiber cloth together with an epoxy resin matrix, in this case the resin "Maxepox CS". The mechanical characteristics of the composite material are summarized in Table 6.

Table 6. Mechanical characteristics of the composite material.

\begin{tabular}{cccc}
\hline Thickness $(\mathrm{mm})$ & 0.163 & 0.727 & 0.890 \\
Tensile strength $\left(\mathrm{N} / \mathrm{mm}^{2}\right)$ & 2400 & 29 & 444 \\
Elasticity module $\left(\mathrm{N} / \mathrm{mm}^{2}\right)$ & $4.4 \times 10^{5}$ & $0.015 \times 10^{5}$ & $0.81 \times 10^{5}$ \\
\hline
\end{tabular}

\subsubsection{Primer}

A primer was used achieve a perfect surface finish prior to the introduction of the shear reinforcement. The main mechanical characteristics of the primer provided by the manufacturer are summarized in Table 7.

Table 7. Mechanical characteristics of the primer.

\begin{tabular}{lcc}
\hline Temperature of employment & Main agent & $15-35^{\circ} \mathrm{C}$ \\
\hline Appearance & Hardener & $\begin{array}{c}\text { Pale liquid } \\
\text { Pale yellow liquid }\end{array}$ \\
\hline Proportion of the mixture: & & $4: 1$ \\
In weigh (A:B) & & $100: 28$ \\
In volume (A:B) & Main agent & 1.15 \\
\hline Specific weight $\left(25^{\circ} \mathrm{C}\right)$ & Hardener & 0.96 \\
\hline & $30^{\circ} \mathrm{C}$ & $90 \mathrm{~min}$ \\
Life time in container $(\mathrm{min})$ & $25^{\circ} \mathrm{C}$ & $130 \mathrm{~min}$ \\
& $15^{\circ} \mathrm{C}$ & $180 \mathrm{~min}$ \\
\hline & $30^{\circ} \mathrm{C}$ & 8.0 \\
Open time $(\mathrm{h})$ & $25^{\circ} \mathrm{C}$ & 11.0 \\
& $15^{\circ} \mathrm{C}$ & 17.0 \\
\hline & $30^{\circ} \mathrm{C}$ & 200 \\
Viscosity & $25^{\circ} \mathrm{C}$ & 320 \\
Performance $\left(\mathrm{Kg} / \mathrm{m}^{2}\right)$ & $15^{\circ} \mathrm{C}$ & 750 \\
\hline Adherence to concrete & & 0.25 \\
\hline
\end{tabular}

\subsection{Testing Campaign}

For the development of the experimental plan, 9 reinforced concrete beams were built at a reduced scale $(20 \times 10 \times 110 \mathrm{~cm})$.

The beams were divided into three batches to statistically contrast the results. The distribution of the batches was as follows:

- Batch A: Beams without reinforcement

- Batch B: Beams with passive reinforcement

- Batch C: Beams with active reinforcement.

Once the characterization of all the materials was carried out, the beams of batches B and C were reinforced. 


\subsubsection{Beams Manufacturing}

A total of $9 \mathrm{RC}$ beams were produced with scaled dimensions of $10 \times 20 \times 120 \mathrm{~cm}$. The scaling factor used was 2.4, and the goal was to be able to handle the beams without the help of heavy mechanical equipment.

A longitudinal and transversal reinforcement was installed in all the beams, as shown in Figure 1.

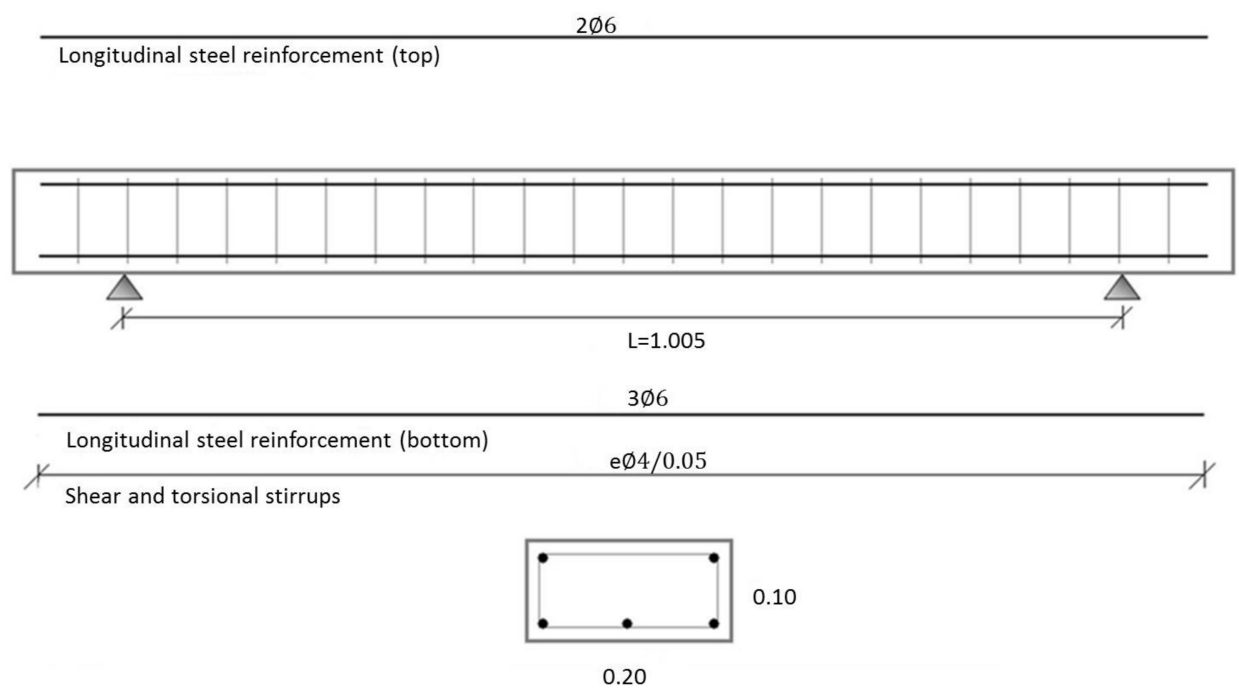

Figure 1. Armature of the beams. All units in $\mathrm{mm}$.

The following figure shows the geometry of the section of the tested beams; of special relevance is the coating of $1 \mathrm{~cm}$ of the reinforcements. The said coating had to be thick enough to allow for the installation of the NSM reinforcements, as shown in Figure 2.

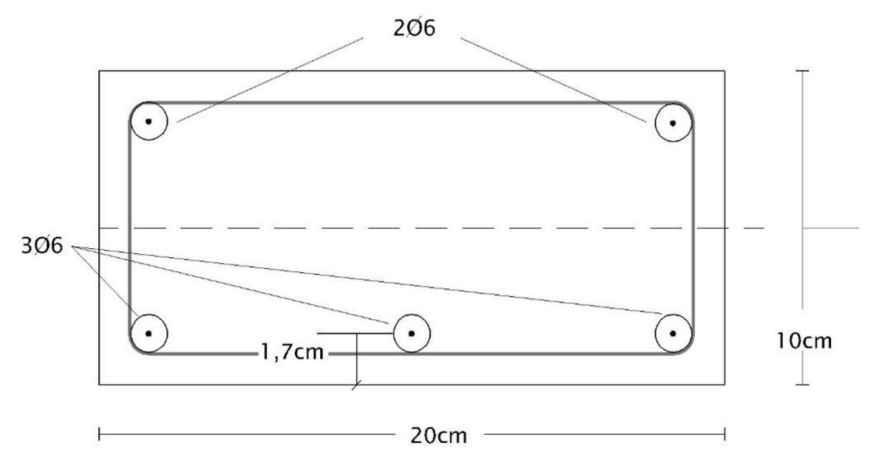

Figure 2. Section of the beams.

A summary of the main characteristics of the beams used in the theoretical calculations is included below:

- $\quad$ Edge $(\mathrm{h})=10 \mathrm{~cm}$

- Width (b) $=20 \mathrm{~cm}$

- Coating $(\mathrm{r})=1.2 \mathrm{~cm}$

- Cross section $(\mathrm{bxh})=200 \mathrm{~cm}^{2}$

- Area of the traction frame-3Ø6 $\mathrm{mm}\left(\mathrm{A}_{\mathrm{s}}\right)=0.85 \mathrm{~cm}^{2}$

- Compression frame-2Ø6 mm $\left(\mathrm{A}_{\mathrm{s}^{\prime}}\right)=0.57 \mathrm{~cm}^{2}$

- Transverse frame- $\varnothing 4 \mathrm{~mm}$ to $5 \mathrm{~cm}$

- Reinforcement area-2Ø8 $\left(\mathrm{A}_{\mathrm{r}}\right)=1.01 \mathrm{~cm}^{2}$

- Characteristic compression strength of concrete $\left(f_{c k}\right)=25.34 \mathrm{~N} / \mathrm{mm}^{2}$ 
- Characteristic tensile strength of concrete $\left(\mathrm{f}_{\mathrm{ctk}}\right)=2.73 \mathrm{~N} / \mathrm{mm}^{2}$

- Concrete elasticity modulus $\left(\mathrm{E}_{\mathrm{c}}\right)=30001.65 \mathrm{~N} / \mathrm{mm}^{2}$ (according to tests)

- Steel elastic limit $\left(\mathrm{f}_{\mathrm{y}}\right)=517.50 \mathrm{~N} / \mathrm{mm}^{2}$ (according to tests)

- Steel elasticity modulus $\left(\mathrm{E}_{\mathrm{s}}\right)=210,000 \mathrm{~N} / \mathrm{mm}^{2}$

- $\quad$ Reinforcement elasticity modulus $\left(E_{\mathrm{r}}\right)=150,000 \mathrm{~N} / \mathrm{mm}^{2}$

Once the characteristics and dimensions of the beams were designed, we proceeded to manufacture the formwork, carry out the assembly of the steel reinforcements, and then complete the making and pouring of the concrete, the demolding process, and the curing process.

The curing and preservation of both the cylindrical test pieces and the beams was carried out in a humid chamber at a temperature of $20 \pm 2{ }^{\circ} \mathrm{C}$ and a relative humidity greater than $90 \%$, following the specifications of the standard [31].

The 9 fabricated beams were divided into three batches of the same size, in order to compare the results.

\subsubsection{Beam Reinforcement}

A theoretical analysis was made to design the reinforcements, taking as a starting point the moment of exhaustion of the section in non-reinforced beams. Based on previous work $[16,19]$ the moment of exhaustion of the passive reinforcement and the moment of exhaustion of the compression concrete was determined. The difference between these two moments constitutes the maximum reinforcement that can be introduced efficiently in the beam, in such a way that both failure mechanisms occur simultaneously. Studying the failure modes, it was concluded that reinforced beams would undergo shear failure [17]. In order to achieve a flexural fracture and to be able to quantify the effects of the reinforcement introduced, the beams were reinforced against shear stresses, by incorporating rings of carbon fiber fabrics glued with epoxy resin in the critical sections.

The results of the theoretical analysis were the following:

- Cracking moment: $\mathrm{M}_{\mathrm{f}}=1.1 \mathrm{KN}-\mathrm{m}$ and $\mathrm{P}=6.6 \mathrm{KN}$.

- Momentum of ductile exhaustion of the beam without reinforcement: $\mathrm{M}_{\mathrm{u}}=3.18 \mathrm{KN}-\mathrm{m}$ and $\mathrm{P}_{\mathrm{u}}=19 \mathrm{KN}$

- Maximum momentum the beam can support before crushing the concrete in the compressed block: $\mathrm{M}_{\max }=8.45 \mathrm{KN}-\mathrm{m}$ and $\mathrm{P}_{\max }=50 \mathrm{KN}$.

CFRP rods of $8 \mathrm{~mm}$ in diameter were available as flexing reinforcement elements. The technique developed to introduce an active load in the reinforcement requires that the number of rods be even, so that finally two reinforcing rods were placed in each of the beams of batches B and C.

The tensile load necessary to balance the resistant capacity of the compressed concrete block was $118 \mathrm{KN}$ and the two CFRP rods used can support up to $200 \mathrm{KN}$, although with a deformation higher than $10 \%$. When dimensioning the passive and active reinforcement, the deformation diagram proposed by the EHE-08 was adopted, introducing a new pivot point $\mathrm{R}$ that represents the deformation of the reinforcement.

Passive reinforcement (Batch B)

This batch was reinforced for flexing with two rods of CFRP per beam, arranged longitudinally on the traction face, as shown in Figure 3. 


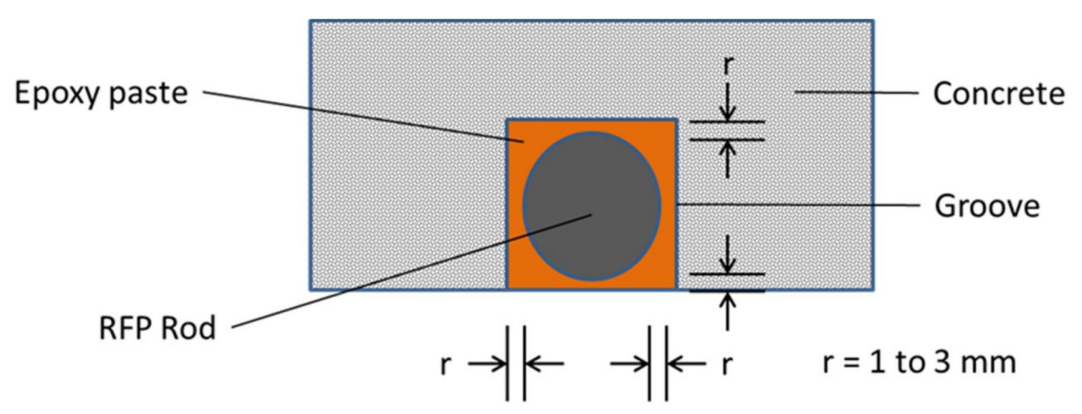

Figure 3. Cross section of the reinforced section, showing the detail of a reinforcement rod.

The reinforcement pivot point $\mathrm{R}$ is introduced in the diagram of deformation domains. A point for a depth of $9.4 \mathrm{~cm}$ from the compressed face corresponds to $3.55 \%$ of deformation.

When point $\mathrm{R}$ is located at $4 \%$ (slightly higher than $3.55 \%$ ), steel exceeds $2.5 \%$. The behavior of the beam is of cracked elastic type, which produces a displacement towards the upper face of the neutral axis. The position of the neutral fiber and the resistant momentum in this situation was then established.

\section{Active reinforcement (Batch C)}

Batch $C$ was reinforced against flexing stress with two rods of CFRP per beam, in which a preload was introduced. The procedure used is described in Section 5 of this article.

When reinforcing a beam in service, the goal of introducing a pre-load on the reinforcement should be mainly to eliminate the initial service arrow and reduce the deformation of the passive steel, transferring the stress to the reinforcement. It is theoretically proposed to deform the reinforcement in a proportion similar to the admissible tensile stress of concrete $\mathrm{f}_{\mathrm{ct}}=2.73 \mathrm{~N} / \mathrm{mm}^{2}$, which requires a force of $13.6 \mathrm{KN}$, with a deformation of $910^{-4}$.

\section{Shear reinforcement}

Previous studies suggested that the failure mechanism of flexion reinforced beams would be through shear stress [17]. In fact, flexural failure was estimated to occur with loads that would generate shear forces of $30 \mathrm{KN}$, much higher than those tolerated by the beam. An objective of the investigation was to study the behavior of the reinforcement in flexion, hence the beams were reinforced against shear stresses.

\subsubsection{Flex Testing}

Flex testing was carried out to study the behavior and failure modes of the beams. The central portion of the beams was subjected to a pure bending moment, and the two lateral thirds undergone a bending moment that varies linearly and a constant shear stress [17]. The points of application of the load were of special interest for the study, because they simultaneously experienced the maximum shear and bending forces. The scheme of loads is shown in Figure 4.

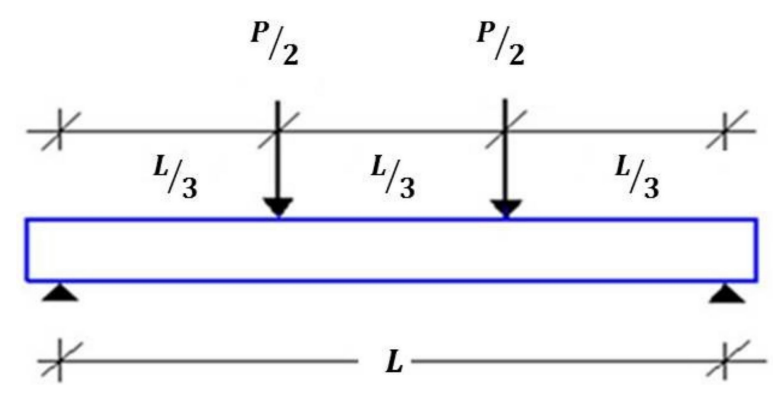

Figure 4. Scheme of loads used in the bending tests. 
The load was introduced by means of a hydraulic jack operated by a press. The load was distributed by means of loading pins in two points as per the figure above, with an approximate speed of $0.5 \mathrm{kN} / \mathrm{s}$. Short steps of load were made to control the cracking.

\section{Results and Discussion}

The results obtained in the tests for beams without reinforcement (Batch A), beams with passive reinforcement (Batch $B$ ) and beams with active reinforcement (Batch $C$ ) are presented and discussed below.

\subsection{Beams without Reinforcement (Batch A)}

The experimental results were as expected. This finding corroborated the theoretical approach and the formulas used were correct.

The initial behavior of these beams was that of a homogeneous section, with the first cracks appearing with a load close to $6 \mathrm{KN}$. When the load went up to $10 \mathrm{KN}$, the cracks in the central portion of the beam became more evident with a vertical configuration, which indicated that the neutral axis moved upwards and the behavior of the beam was no longer homogeneous but elastic. In the load-deflection diagram (measured in the middle section of the beam), the change from homogeneous to elastic behavior can clearly be observed. It can be said that the end of the elastic phase is the one that corresponds to a load of approximately $20 \mathrm{KN}$, in line with the theoretical model proposed. As the load kept increasing and the compressed block continued to be reduced, the first shear cracks appeared. It should be noted that the beams of Batch A did not have shear reinforcement. Finally, all beams underwent ductile failure for loads between $25 \mathrm{KN}$ and $27 \mathrm{KN}$.

\subsection{Beams with Passive Reinforcement (Batch B)}

The behavior of these beams was different from that observed in batch A, highlighting an increase in rigidity which resulted in a lower deflection for similar loads. The theoretical load was calculated for a deformation of $4 \%$, with which an arrow was obtained in the center of the span of approximately $6.5 \mathrm{~mm}$ during the tests. The three beams had a similar behavior up to the load of $40 \mathrm{KN}$, at which point the discrepancy introduced by the greater length in the anchors of the flexing reinforcements of Beam 4 becomes apparent.

\subsection{Beams with Active Reinforcement (Batch C)}

All the beams of Batch $C$ had an elastic behavior until the moment of failure, which was produced by shear stress.

The results obtained with the tests of beam V-7 were satisfactory: there was a substantial reduction in the cracking and the arrow in the center of the span in the first loading steps, in comparison with the beams of batches $\mathrm{A}$ and $\mathrm{B}$.

It must be noted however that upon close examination of the broken section it was observed how the epoxy adhesive had failed to fully penetrate the groove, probably due to its high viscosity. As a result, the rod was not fully embedded in the adhesive, which may have limited the effectiveness of the reinforcement.

\subsection{Comparative Results of the Flexural Tests of the Three Batches}

Table 8 shows the empirical and theoretical results of the different batches tested: 
Table 8. Experimental and theoretical results of the beams tested.

\begin{tabular}{|c|c|c|c|c|c|c|}
\hline \multirow[b]{2}{*}{ Batch } & \multirow[b]{2}{*}{ Beam } & \multicolumn{2}{|c|}{ Cracking } & \multicolumn{2}{|c|}{ Elastic-Cracked } & \multirow{2}{*}{$\begin{array}{c}\text { Depletion } \\
\begin{array}{c}\text { Load } \\
(\mathrm{kN})\end{array}\end{array}$} \\
\hline & & $\begin{array}{l}\text { Load } \\
(k N)\end{array}$ & $\begin{array}{l}\text { Deflection } \\
(\mathrm{mm})\end{array}$ & $\begin{array}{l}\text { Load } \\
(\mathrm{kN})\end{array}$ & $\begin{array}{c}\text { Deflection } \\
(\mathrm{mm})\end{array}$ & \\
\hline \multirow{4}{*}{ Batch A } & V-1 & 5.7 & 0.37 & 21.8 & 5.64 & 28.0 \\
\hline & $\mathrm{V}-2$ & 5.7 & 0.8 & 20.9 & 6.68 & 25.7 \\
\hline & V-3 & 4.6 & 0.49 & 21.1 & 5.87 & 25.3 \\
\hline & Theoretical & 5.4 & 0.34 & 14.9 & 7.09 & 18.1 \\
\hline \multirow{4}{*}{ Batch B } & $\mathrm{V}-4$ & 6.4 & 0.52 & 61.2 & 11.08 & 63.0 \\
\hline & V-5 & 4.4 & 0.38 & 44.1 & 7.76 & 48.0 \\
\hline & V-6 & 6.0 & 0.48 & 49.0 & 9.21 & 51.0 \\
\hline & Theoretical & 5.5 & 0.33 & 33.0 & 15.7 & \\
\hline \multirow{4}{*}{ Batch C } & V-7 & 8.7 & 0.67 & 73.3 & 14.43 & 75.6 \\
\hline & $\mathrm{V}-8$ & 8.5 & 0.41 & 47.8 & 8.27 & 51.5 \\
\hline & V-9 & NA & NA & 64.1 & 13.17 & 64.4 \\
\hline & Theoretic & 6.9 & 0.41 & 34.3 & 16.4 & \\
\hline
\end{tabular}

Figure 5 represents the load-arrow diagram in the center of the span for beams V-3, V-4 and V-7, which are the most representative of each batch.

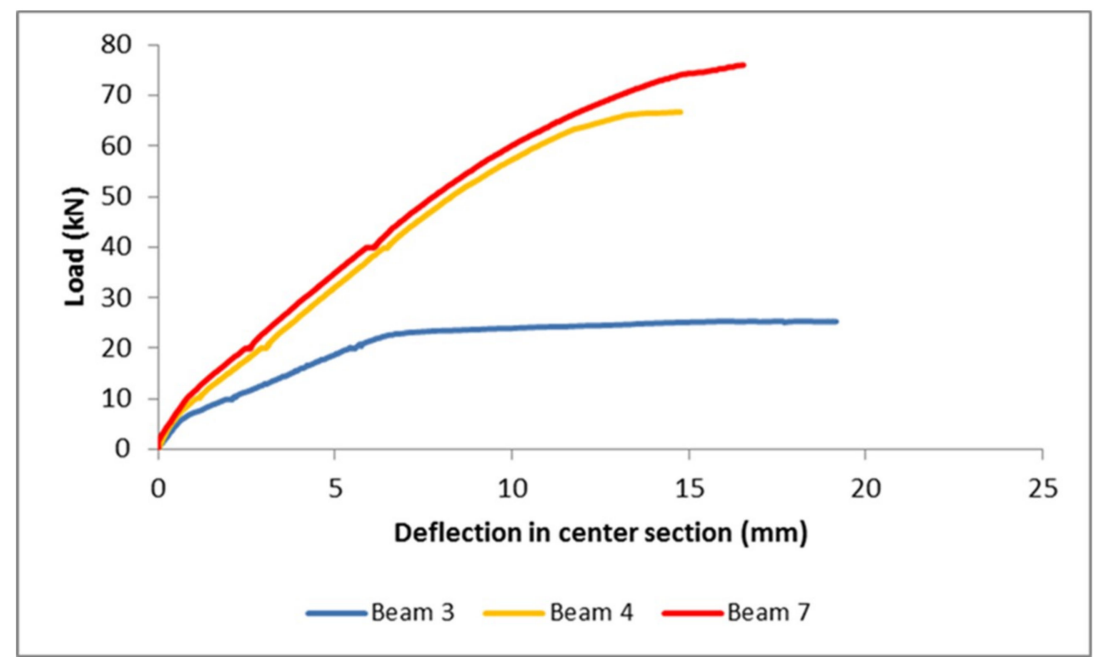

Figure 5. Load-deflection diagram in center section for the most representative beams of each batch.

From the above figure it can be clearly seen the influence of the reinforcement that was introduced. However, there doesn't seem to be a significant difference between beams 4 and 7 . Upon visual inspection of the beams after the tests were carried out, it could be observed that the prestressing of beam 7 was somewhat defective: since the epoxy adhesive, which presented a high viscosity, was put in the grooves after the rods, it had difficulties filling all the empty space between the grooves and the rods. This could have been easily solved by placing the adhesive before the rods in the grooves. As a result, only a partial bundling of the presetressed rods and the RC was achieved.

\section{Conclusions}

Reinforcements with prestressed CFRP in NSM configuration is a thriving research field. However, the introduction of preloads on the reinforcement is a complex task, and the majority of the studies carried out so far use methods that act and react against external elements. This paper proposes and tests a method that introduces the preloads on the bars after they have been mounted on the RC beam, acting and reacting against the beam itself. 
According to the theoretical and experimental results obtained, the main conclusions are as follows:

- The introduction of preloads in reinforcement improves the mechanical behavior of the beam, thus making more efficient use of the characteristics of the reinforcement material. The active reinforcement supposes an increase of $170 \%$ of failure load with respect to the control beam.

- The introduction of preloads in the flexion reinforcement is complicated. Although it has been possible to achieve conditions close to those of a working site in the experiments, it will be necessary to improve the injection technique of the structural adhesive, to eliminate the cavities that appeared during the tests in beams from Batch C.

Future research could test the method proposed in this paper, adapting it in order to ensure the absence of cavities in the grooves made in the RC beam. This could allow determining to what extent the prestressing introduced improves a passive reinforcement. Also, theoretical formulas to predict the results of the reinforcements introduced with this technique could be developed.

\section{Patents}

This section describes the pre-stressing technique for NSM rods that has been developed, patented and tested.

Other authors have developed NSM rod pre-stressing techniques under laboratory conditions. These studies highlight the practical difficulties that arise when carrying out a reinforcement of this type $[18,20,22,23]$. The main drawback that has been identified is access to the ends of the beam to be reinforced. Ingenious solutions were designed to overcome this drawback, but they still presented serious drawbacks such as low productivity, the difficulty of accurately determining the load introduced into the bars and above all implementation outside the laboratory.

We developed an original system designed to overcome some of these problems. The procedure has been patented under the title "Method and system for tensioning rods applied to the reinforcement of structural elements". It can be applied for both flexural and shear reinforcement of RC structures.

The method consists of several stages, some of them similar to those of an ordinary NSM reinforcement:

1. The process begins by producing superficial straight cuts in the structural element of RC, with a depth equivalent to the shear and torsional stirrups, and the help of a radial tool. The symmetry has to be kept in line with the longitudinal axis of the structural element to be reinforced; in this case the longitudinal axis of the beam, as shown in Figure 6.

2. Next, the FCRP rods are placed inside the cuts, together with load distribution elements (metal plates or similar) at each end, which will distribute the load received during the introduction of the pre-loads and thus avoid damaging the concrete, as shown in Figure 7.

3. A reaction element against which a traction system can push is put in place, as shown in Figure 8 . Such an element must be very rigid and with perforations or grooves that are crossed by the FRP rods.

4. The anchoring of the ends of the rods to immobilize them is achieved by means of a passive anchorage at one of the ends, and an active anchorage at the other end. They rely on the adhesion developed between the epoxy resin and the reinforcement rod. The anchor length is determined as a function of the pre-load that is intended to be introduced. In the first method, epoxy resin is injected into a copper tube of a diameter larger than the diameter of the FRP rod, placed perfectly centered at one end of the rod.

5. After the rods are fixed, a traction system is placed, which can be a hydraulic jack or similar, as shown in Figure 9. Once balanced, the load begins to be applied, until the desired traction is obtained. Ideally the jack would have a pressure gauge to determine the preload introduced into the rods. 
6. To avoid the loss of load due to the relaxation of the traction system, it is preferable to immobilize the traction system and the pushing element against which the traction system pushes. This is achieved by placing at least one supplement that immobilizes the reaction element. In this way it is also possible to remove the traction system without the rods losing the load that has been introduced. In the tests carried out some wooden blocks were used, although certain load losses were recorded.

7. Finally, the tensioned rods are glued along the entire connection to the structural element of concrete. For instance, epoxy resin can be used, by pouring it in the grooves in which the rods are located, and trying to completely fill the cuts made. Alternatively, it would also be possible to pre-fill the cuts in the structural element to be reinforced before placing the rods, to improve their filling.

8. When the resin hardens, all the auxiliary elements (anchoring systems, load distribution plates, reaction system) can be removed. It will also be necessary to cut the protruding rods at both ends.

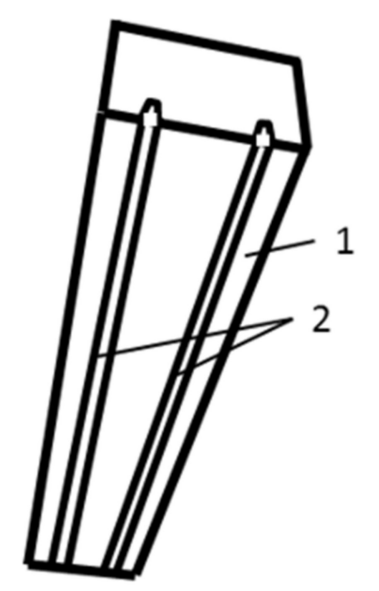

1. Structural RC element to be reinforced

2. Cuts symmetrical cuts into the RC

element

Figure 6. Step 1 of the proposed prestressing process.

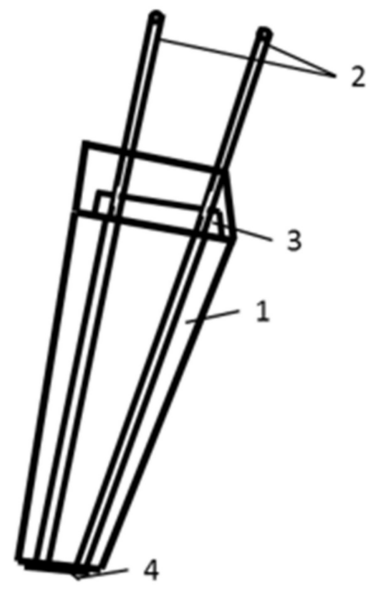
1. Structural RC element to be reinforced
2. FRP rods
3. Load distribution element
4. Load distribution element

Figure 7. Step 2 of the proposed prestressing process. 


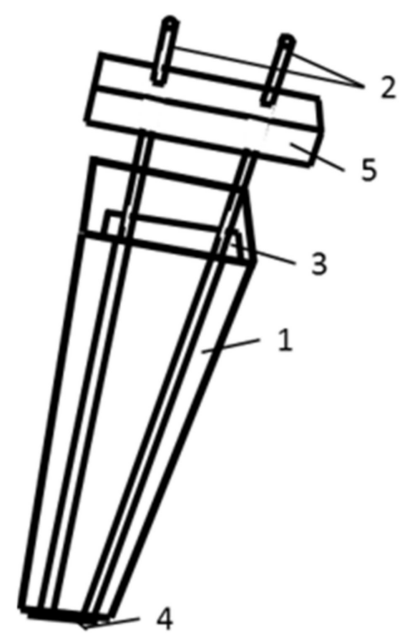

1. Structural RC element to be reinforced

2. FRP rods

3. Load distribution element

4. Load distribution element

5. Reaction element

Figure 8. Step 3 of the proposed prestressing process.

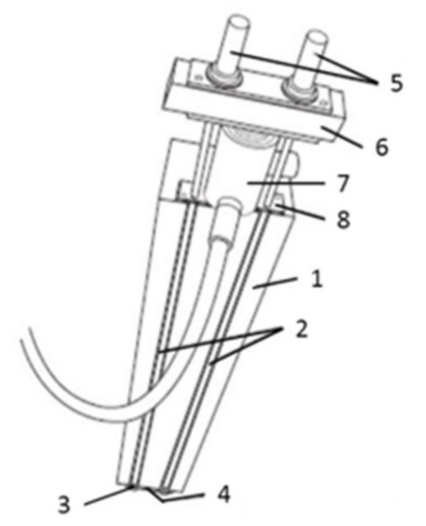

1. Structural RC element to be reinforced

2. FRCP rods

3. Passive anchoring

4. Load distribution element

5. Active anchoring

6. Reaction element

7. Traction system (Jack)

8. Load distribution element

Figure 9. Diagram of the proposed system for the pre-stressing of NSM rods in a flexural reinforcement with all its elements in place.

The system described above can easily be replicated under laboratory conditions, but may present some challenges outside the laboratory. In real situations it might be necessary to adapt the method and introduce some modifications, as shown in Figure 10 for instance.

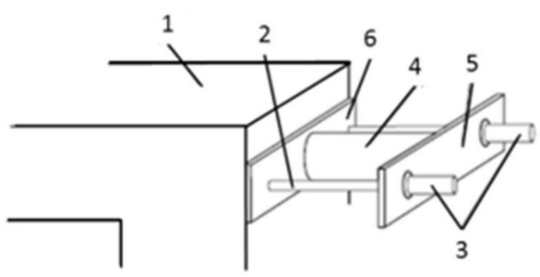
1. Structural RC element to be reinforced
2. FRCP rods
3. Active anchoring
4. Traction system (Jack)
5. Reaction element
6. Load distribution element

Figure 10. Modification of the pre-stressing method when it is necessary to cross a structural element.

Author Contributions: The conceptualization and methodology work that led to the development of the patent described in this article was done by A.L.P. and V.A.C.A., E.M.G.d.T. and M.I.M.-L. contributed in the data validation and formal analysis of the experimental campaign.

Funding: This research received no funding.

Acknowledgments: The reinforcement materials needed for this research were provided by DRIZORO S.L. The testing campaign was conducted in the laboratories of the Instituto Torroja, CSIC, Spain.

Conflicts of Interest: The authors declare no conflict of interest. 
Appendix A -Granulometric Analysis of the Sand and the Gravel Used in the Testing Campaign

Table A1. Granulometric analysis of the sand used in the experimental phase.

\begin{tabular}{cccc}
\hline UNE Sieves (mm) & \% Retained Sand & $\begin{array}{c}\text { \% Retained Sand } \\
\text { Accumulated }\end{array}$ & $\begin{array}{c}\text { \% Accumulated } \\
\text { Passing Sand }\end{array}$ \\
\hline 32 & 0.00 & 0.00 & 100.00 \\
16 & 0.00 & 0.00 & 100.00 \\
8 & 0.00 & 0.00 & 100.00 \\
4 & 1.48 & 1.48 & 98.52 \\
2 & 17.18 & 18.67 & 81.33 \\
1 & 34.27 & 52.94 & 47.06 \\
0.5 & 22.30 & 75.24 & 24.76 \\
0.25 & 16.63 & 91.87 & 8.13 \\
0.125 & 6.80 & 98.67 & 1.33 \\
0.063 & 1.33 & 100.00 & 0.00 \\
\hline
\end{tabular}

Table A2. Granulometric analysis of the gravel used in the experimental phase.

\begin{tabular}{cccc}
\hline UNE Sieves $(\mathbf{m m})$ & \% Retained Sand & $\begin{array}{c}\text { \% Retained Sand } \\
\text { Accumulated }\end{array}$ & $\begin{array}{c}\text { \% Accumulated } \\
\text { Passing Sand }\end{array}$ \\
\hline 32 & 0 & 0 & 100 \\
16 & 0 & 0 & 100 \\
8 & 32.56 & 32.56 & 67.44 \\
4 & 64.36 & 96.92 & 3.08 \\
2 & 2.15 & 99.07 & 0.93 \\
1 & 0.24 & 99.31 & 0.69 \\
0.5 & 0.05 & 99.36 & 0.64 \\
0.25 & 0.06 & 99.42 & 0.58 \\
0.125 & 0.09 & 99.51 & 0.49 \\
0.063 & 0.50 & 100 & 0 \\
\hline
\end{tabular}

\section{References}

1. Aslam, M.; Shafigh, P.; Jumaat, M.Z.; Shah, S.N.R. Strengthening of RC beams using prestressed fiber reinforced polymers-A review. Constr. Build. Mater. 2015, 82, 235-256.

2. Feng, Q.; Cui, J.; Wang, Q.; Fan, S.; Kong, Q. A feasibility study on real-time evaluation of concrete surface crack repairing using embedded piezoceramic transducers. Measurement 2018, 122, 591-596. [CrossRef]

3. Qeshta, I.M.I.; Shafigh, P.; Jumaat, M.Z. A Research progress on the flexural behaviour of externally bonded RC beams. Arch. Civ. Mech. Eng. 2016, 16, 982-1003.

4. Breveglieri, M.; Barros, J.; Dalfré, G.; Aprile, A. A parametric study about the effectiveness of the NSM technique for the flexural strengthening of continuous RC slabs. Compos. Part. B Eng. 2012, 43, 1970-1987.

5. Ahmad, S. Reinforcement corrosion in concrete structures, its monitoring and service life prediction-A review. Cem. Concr. Compos. 2003, 25, 459-471.

6. Abdelrahman, A.A.; Rizkalla, S.H. Serviceability of concrete beams prestressed by carbon-fiber-reinforced-plastic bars. ACI Struct. J. 1997, 94, S42.

7. De-Lorenzis, L.; Teng, J. Near-surface mounted FRP reinforcement: An emerging technique for strengthening structures. Compos. Part. B Eng. 2007, 38, 119-143.

8. Khalifa, A.; Alkhrdaji, T.; Nanni, A.; Lansburg, S. Anchorage of surface mounted FRP reinforcement. Concr. Int. Des. Constr. 1999, 21, 49-54.

9. Yost, J.; Gross, S.; Dinehart, D.; Mildenberg, J. Flexural behavior of concrete beams strengthened with near-surface-mounted CFRP strips. ACI Struct. J. 2007, 104, 430-437. 
10. El-Hacha, R.; Riskalla, S. Near-surface-mounted fiber-reinforced polymer reinforcements for flexural strengthening of concrete structures. ACI Struct. J. 2004, 101, 717-726.

11. Soliman, S.; El-Salakawy, E.; Benmokrane, B. Flexural behaviour of concrete beams strengthened with near surface mounted fibre reinforced polymer bars. Can. J. Civ. Eng. 2010, 37, 1371-1382. [CrossRef]

12. De-Lorenzis, L.; Nanni, A. Bond between near-surface mounted FRP rods and concrete in structural strengthening. ACI Struct. J. 2002, 99, 123-132.

13. Hassan, T.; Rizkalla, S. Investigation of Bond in Concrete Structures Strengthened with Near Surface Mounted Carbon Fiber Reinforced Polymer Strips. J. Compos. Constr. 2003, 7, 248-257. [CrossRef]

14. Hassan, T.; Rizkalla, S. Bond Mechanism of NSM FRP Bars for Flexural Strengthening of Concrete Structures. ACI Struct. J. 2004, 101, 830-839.

15. Chalioris, C.E.; Kosmidou, P.K.; Papadopoulos, N.A. Investigation of a New Strengthening Technique for RC Deep Beams Using Carbon FRP Ropes as Transverse Reinforcements. Fibers 2018, 6, 52. [CrossRef]

16. Kim, Y.J.; Heffernan, P.J. Fatigue behavior of externally strengthened concrete beams with fiber-reinforced polymers: State of the art. J. Compos. Constr. 2008, 12, 246-256. [CrossRef]

17. Luizaga, A.M. Comportamiento Mecánico de Vigas de Hormigón Reforzadas con Bandas Encoladas con Resinas Epoxídicas. Ph.D. Thesis, Universidad Politécnica de Madrid, Madrid, Spain, 2005.

18. Nordin, H.; Taljsten, B. Concrete beams strengthened with prestressed near surface mounted CFRP. J. Compos. Constr. 2006, 10, 60-68. [CrossRef]

19. Meier, U. Strengthening of structures using carbon fibre/epoxy composites. Constr. Build. Mater. 1995, 9, 341-351. [CrossRef]

20. El-Hacha, R.; Gaafar, M. Flexural strengthening of reinforced concrete beams using prestressed, near-surface-mounted CFRP bars. PCI J. 2011, 56, 134-151. [CrossRef]

21. Oudah, F.; El-Hacha, R. Analytical fatigue prediction model of RC beams strengthened in flexure using prestressed FRP reinforcement. Eng. Struct. 2013, 46, 173-183. [CrossRef]

22. Badawi, M.; Soudki, K. Flexural strengthening of RC beams with prestressed NSM CFRP rods-Experimental and analytical investigation. Constr. Build. Mater. 2009, 23, 3292-3300. [CrossRef]

23. Rezazadeh, M.; Ramezansefat, H.; Barros, J. NSM CFRP Prestressing Techniques with Strengthening Potential for Simultaneously Enhancing Load Capacity and Ductility Performance. J. Compos. Constr. 2016, 20, 04016029. [CrossRef]

24. Rezazadeh, M.; Barros, J.; Costa, I. Analytical approach for the flexural analysis of RC beams strengthened with prestressed CFRP. Compos. Part B Eng. 2015, 73, 16-34. [CrossRef]

25. Choi, H.T.; West, J.S.; Soudki, K.A. Effect of partial unbonding on prestressed nearsurface- mounted CFRP-strengthened concrete T-Beams. J. Compos. Constr. 2010, 15, 93-102. [CrossRef]

26. Hajihashemi, A.; Mostofinejad, D.; Azhari, M. Investigation of RC beams strengthened with prestressed NSM CFRP laminates. J. Compos. Constr. 2011, 15, 887-895. [CrossRef]

27. Rezazadeh, M.; Costa, I.; Barros, J. Influence of prestress level on NSM CFRP laminates for the flexural strengthening of RC beams. Compos. Struct. 2014, 116, 489-500. [CrossRef]

28. Instituto Nacional de Racionalización y Normalización. UNE 80-103-86: Métodos de Ensayo de Cementos: Ensayos Físicos: Determinación de la Densidad real Mediante el Volumenómetro de Le Chatelier; IRANOR: Madrid, Spain, 1986.

29. Instituto Nacional de Racionalización y Normalización. UNE-EN 1097-6:2014: Tests for Mechanical and Physical Properties of Aggregates_Part 6: Determination of Particle Density and Water Absorption; AENOR: Madrid, Spain, 2014.

30. Instituto Nacional de Racionalización y Normalización. UNE-EN 12620:2003: Aggregates for Concrete; AENOR: Madrid, Spain, 2003.

31. Instituto Nacional de Racionalización y Normalización. UNE 83301:1991: Tests of Concrete. Making and Curing of Specimens; AENOR: Madrid, Spain, 1991.

32. Instituto Nacional de Racionalización y Normalización. UNE-EN 12390-3:2003: Testing Hardened Concrete-Part 3: Compressive Strength of Test Specimens; AENOR: Madrid, Spain, 2003.

(C) 2019 by the authors. Licensee MDPI, Basel, Switzerland. This article is an open access article distributed under the terms and conditions of the Creative Commons Attribution (CC BY) license (http:/ / creativecommons.org/licenses/by/4.0/). 